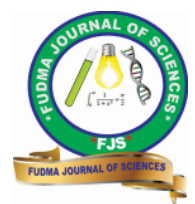

FUDMA Journal of Sciences (FJS)

ISSN online: 2616-1370

ISSN print: 2645 - 2944

Vol. 4 No. 3, September, 2020, pp $591-600$

DOI: https://doi.org/10.33003/fjs-2020-0403-328

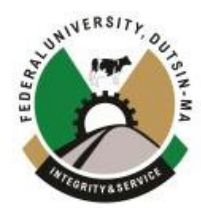

\title{
PHOTOCATALYST: A PROMISING SMART MATERIAL IN DEGRADATION OF DYE USING RESPONSE SURFACE METHODOLOGY (RSM)
}

\author{
Abubakar, A and Nuraddeen, A \\ Department of Pure and Industrial Chemistry, Faculty of Natural and Applied Science, Umaru Musa Yar'adua \\ University, Katsina State, Nigeria \\ *Corresponding Author's Email: abduljozy79@gmail.com
}

\begin{abstract}
One of the environmental issues is water Pollution causing serious health related problem not only to human but also seriously affect aquatic life. Dyes are among the pollutants that pollute our water bodies. In the olden days so many methods were applied for the purification of water but recently photocatalysis shown a promising technique where the pollutants (dyes) were degraded to give clean water and carbon dioxide to be liberated as the end product. The specific surface area of the photocatalyst $243.80 \mathrm{~m}^{2} \mathrm{~g}^{-1}$ and the PZC was found to be 8.10 . Only $0.9 \%$ of the dye (MG) decolorized in the presence of light (photolysis) while $25 \%$ of the MG was adsorbs in the dark with 30 minutes of contact. The ANOVA showed an F-value of 1114.81 which suggests that the model is significant. All model terms i.e. MG initial concentration, photocatalyst dose, irradiation period and $\mathrm{pH}$ are all significant with Prob $>$ " values $<0.05$. The predicted R-squared that has a value 0.995 was in perfect agreement reasonably with Adj R-squared that reached up to $99.8 \%$. Adequate precision more than 4.00 by this model indicates desirable and adequate signal. The influence of MG initial concentration in removing the MG color was higher when compared to other parameters involved and this was indicated by the F-values.
\end{abstract}

Keywords: Malachite green (MG), Point of Zero charge (PZC), Dye, $\mathrm{ZnFe}_{2} \mathrm{O}_{4} / \mathrm{TiO}_{2}$ composite, CCD.

\section{INTRODUCTION}

Photocatalytic decolorization of dyes using $\mathrm{TiO}_{2}$ has been studied in the past by various researchers (Behnajady et al., 2007). Various types of dyes were used by textile industries. Malachite green dye (MG) with molecular formula $\mathrm{C}_{32} \mathrm{H}_{16} \mathrm{~N}_{8} \mathrm{~S}_{2} \mathrm{O}_{6} \mathrm{CuNa}_{2}$ is among the most persistent compared to acidic dye, disperse dye and reactive dye especially when it was used during photocatalysis with a $\mathrm{TiO}_{2}$ (Gallo et al., 2008). The values of the optimize parameters vary depending on the water pollutant targeted, photocatalyst nature and of reaction set-up. Advance Oxidation Process means that very reactive species were generated especially hydroxyl radicals and this radical usually oxidizes most of pollutants very fast and it was non-selective. (Uygur, 1997) removed azo dyes using Advance Oxidation Process. (Aplin and Waite, 2000) used this same process in photo- Fenton reaction of hydrogen peroxide, $\mathrm{Fe}^{2+}$ $/ \mathrm{H}_{2} \mathrm{O}_{2}$ while (Moraes et al., 2000) applied UV in the photocatalysis of hydrogen peroxide, $\mathrm{H}_{2} \mathrm{O}_{2} / \mathrm{UV}$ and (Masten and Davies, 1994) also used $\mathrm{TiO}_{2} / \mathrm{UV}$ in decomposing hydrogen peroxide.

In our study, Design expert software v6 compose of Response Surface Methodology was used in carrying out optimization was also used to generate second order model in which the response variables does not require a three-level factorial experiment. Photocatalysis application in the treatment of textile wastewater is long overdue, until today, (Han et al.,
2008) reported that there is no photocatalytic system world over that is available commercially with high decolorization efficiency, ease in photocatalyst activity and that can be activate easily in visible light.

\section{Photocatalytic design of experiments by R SM}

This approach as implemented in design expert 6.0.6 software (Rezaee et al., 2012), was used to design the photocatalytic experiments. The process variables studied were: initial MG dye concentration (A), photocatalyst dosage (B), irradiation time (C) and the initial pH (D). This method is used in optimizing variables and the variables were considered as independent parameters while decolorization as output response variable. The designed matrix setup was determine using Central Composite Design, consisting 30 experiments as obtained by the equation: $\mathrm{N}=2^{\mathrm{n}}+2 \mathrm{n}+\mathrm{C}_{0}$, where total number of experiments required stands for $\mathrm{N}$, number of variables is $\mathrm{n}$, axial runs stands for $2 \mathrm{n}$ and center point runs is $\mathrm{C}_{0}$. These experiments were all obtained from the above variables $(n=4)$ and at two levels: $(-1)$ stands for low and $(+1)$ for high. Simplifying the above equation the model consist of $2^{\mathrm{n}}\left(2^{4}=16\right.$ factor points, $+(2 \mathrm{n})$ which gives $2 \times 4=8$ : axial points $)+6$, points center, i.e. (six replications). The polynomial response equation generated was used to get interaction between dependent and independent parameters. The polynomial model was expressed as:

$$
\mathrm{Y}=\mathrm{b}_{0}+\sum_{i=1}^{n} b i x i+\left(\sum_{i=1}^{n} b i i x i\right)^{2}+\sum_{i=1}^{n-1} \sum_{j=i+1}^{n} b i j x i x j \ldots \ldots \mathrm{i}
$$

where, $y$ (\%) represents predicted response and is the linear coefficients stands for bi, interaction coefficients, (bij) dependent variable, (decolorization rate of MG efficiency), and quadratic coefficients (bii). Moreover, the coded values / 
independent parameters studied (initial $\mathrm{pH}$, photocatalyst dosage and initial MG concentration) were $\mathrm{xi}$ and $\mathrm{xj}$ and affect the response y. The parameters were related by coefficients. The specific weight of the parameters in the model was indicated by coefficients which also show the performance of the variables in the photodecolorization.

\section{METHODOLOGY}

photodecolorization experiments were performed in a laboratory scale. Decolorizing malachite green dye in aqueous solution was carried out by the as-synthesized $\mathrm{ZnFe}_{2} \mathrm{O}_{4} / \mathrm{TiO}_{2}$ composite. The set-up for the experiment consists of a glass beaker $\left(250 \mathrm{~cm}^{3}\right)$, magnetic stirrer, and a $500 \mathrm{~W}$ halogen lamp Different amounts of the photocatalyst $\left(0.05-1 \mathrm{~g} / 100 \mathrm{~cm}^{3}\right)$ were added into $100 \mathrm{~cm}^{3}$ of MG solution of different concentration (5-20 mg/L). 0.01 $\mathrm{M} \mathrm{HNO}_{3}$ was used for $\mathrm{pH}$ adjustment to the desired $\mathrm{pH}$ (3, 6 and 9). Each of the suspension was magnetically stirred in dark for 30 minutes establishing adsorption/desorption equilibrium before irradiation with 500 $\mathrm{W}$ halogen lamps. The suspension was maintained at room temperature and the distance of the lamp from the solution was $20 \mathrm{~cm} .10 \mathrm{~cm}^{3}$ of the suspension was withdrawn at regular time interval of 30 minutes over irradiation period of 90 minutes. The suspension was centrifuged at $6000 \mathrm{rpm}$ for 10 minutes and filtered to remove the photocatalyst particles before measuring absorbance. The absorbance of the dye left was measured at a $624 \mathrm{~nm}$ (MG, $\left.\lambda_{\max }\right)$ using a UV-vis spectrophotometer (T60 PG instrument). All photodecolorization reactions were performed in triplicate to ensure the reproducibility of the experimental results. The Percentage decolorization rate of MG dye was calculated using the formula.

$\%$ Decolorization $=\mathrm{C}_{0}-\mathrm{C} / \mathrm{C}_{0} \times 100 \ldots \ldots \ldots . \quad$ ii

Where $\mathrm{C}_{0}$ is absorbance before illumination and $\mathrm{C}$ is absorbance after visible light illumination, respectively.

For the (PZC), small amount of the sample $0.5 \mathrm{~g}$ of $\mathrm{ZnFe}_{2} \mathrm{O}_{4}$ $\mathrm{TiO}_{2}$ was added to $40 \mathrm{~cm}^{3}$ of $0.1 \mathrm{M} \mathrm{NaNO}_{3}$ in seven $50 \mathrm{~cm}^{3}$ beakers. The $\mathrm{pH}$ was adjusted to $3,4,5,6,7,8$ and $9( \pm 0.1 \mathrm{pH}$ units). $\quad 0.1 \mathrm{M} \mathrm{HNO}_{3}$ acid and $0.1 \mathrm{M} \mathrm{NaOH}$ were used.
Samples were shaken on a magnetic stirrer over night to reach equilibrium. After this time $\mathrm{pH}$ of each sample was measured as final $\mathrm{pH}$. Then the variation between final $\mathrm{pH}(\Delta \mathrm{pH})$ and initial $\mathrm{pH}\left(\mathrm{pH}_{0}\right)$ values was plotted. $\mathrm{pHzp}^{\mathrm{c}}$ was taken were at zero pH. (Mahmood and Saddique, 2011).

Sear's method was used to estimate Specific surface area (SSA) of the $\mathrm{ZnFe}_{2} \mathrm{O}_{4} / \mathrm{TiO}_{2}$ (Sear's 1959). In this method $0.5 \mathrm{~g}$ of the $\mathrm{ZnFe}_{2} \mathrm{O}_{4} / \mathrm{TiO}_{2}$ sample was agitated in $100 \mathrm{~cm}^{3}$ dilute $\mathrm{HCl}$ of a $\mathrm{pH} 3.20 \mathrm{~g} \mathrm{NaCl}$ was added with stirring and the volume was made up to $150 \mathrm{~cm}^{3}$ with deionized water. The solution was titrated with $0.1 \mathrm{M} \mathrm{NaOH}$ and the volume, (V), needed to raise the $\mathrm{pH}$ from 3- 9 was then recorded. The surface area according to this method was calculated from below equation:

$\mathrm{S}\left(\mathrm{m}^{2} \mathrm{~g}^{-1}\right)=32 \times \mathrm{V}-25 \ldots \ldots \ldots \ldots \ldots \ldots \ldots \ldots i i$

Where $\mathrm{V}$ is the volume of the base required to raise the $\mathrm{pH}$ of the sample from 3-9. This volume was measured in replicate and the average value was taken for the surface area calculation.

In the first titration the volume of the base that raised the $\mathrm{pH}$ from 3-9 was $8.40 \mathrm{~cm}^{3}$. For the second titration the volume was $8.38 \mathrm{~cm}^{3}$ and the third titration the volume of the base was 8.42 $\mathrm{cm}^{3}$. The average Titre value of the base used was found to be $8.40 \mathrm{~cm}^{3}$.

$25=243.80 \mathrm{~m}^{2} \mathrm{~g}^{-1}$

\section{Salt addition method: $\mathbf{p H}$ of zero Point of charge $\left({ }_{\mathrm{pHzp}} \mathrm{H}^{\mathrm{c}}\right)$}

$0.5 \mathrm{~g}$ of $\mathrm{ZnFe}_{2} \mathrm{O}_{4} / \mathrm{TiO}_{2}$ was added to $40 \mathrm{~cm}^{3}$ of $0.1 \mathrm{M} \mathrm{NaNO}_{3}$ in seven $50 \mathrm{~cm}^{3}$ beakers to determine $\mathrm{pH}$ of zero Point of charge (PZC). The $\mathrm{pH}$ was adjusted to $3,4,5,6,7,8$ and 9 ( $\pm 0.1 \mathrm{pH}$ units). $0.1 \mathrm{M} \mathrm{HNO}_{3}$ acid and $0.1 \mathrm{M} \mathrm{NaOH}$ were used. Samples were shaken on a magnetic stirrer over night to reach equilibrium. After this time $\mathrm{pH}$ of each sample was measured as final $\mathrm{pH}$. Then variation between the final $\mathrm{pH}(\Delta \mathrm{pH})$ and the initial $\mathrm{pH}\left(\mathrm{pH}_{0}\right)$ values was plotted. $\mathrm{pHzp}^{\mathrm{c}}$ was taken were at zero pH. (Mahmood and Saddique, 2011). The photocatalyst produced was characterized for its specific surface area using sear's Method, Point of zero charge (PZC).

\section{RESULT AND DISCUSSION}

Table 1: Characteristics of $\mathrm{ZnFe}_{2} \mathrm{O}_{4} / \mathrm{TiO}_{2}$ photocatalyst

\begin{tabular}{ll}
\hline Parameter (Unit) & Value \\
\hline Specific surface area $\left(\mathbf{m}^{2} \mathbf{g}^{-1}\right)$ & $243.80 \mathrm{~m}^{2} \mathrm{~g}^{-1}$ \\
Point of zero charge & 8.1 \\
& \\
\hline
\end{tabular}

$\mathrm{ZnFe}_{2} \mathrm{O}_{4} / \mathrm{TiO}_{2}$ have a specific surface area $243.80 \mathrm{~m}^{2} \mathrm{~g}^{-1}$ and the PZC of the photocatalyst is 8.10 . Excellent adsorption of MG molecules onto the surface of $\mathrm{ZnFe}_{2} \mathrm{O}_{4} / \mathrm{TiO}_{2}$ is expected at basic $\mathrm{pH}$ of dye solution since $\mathrm{MG}$ is cationic dye. 


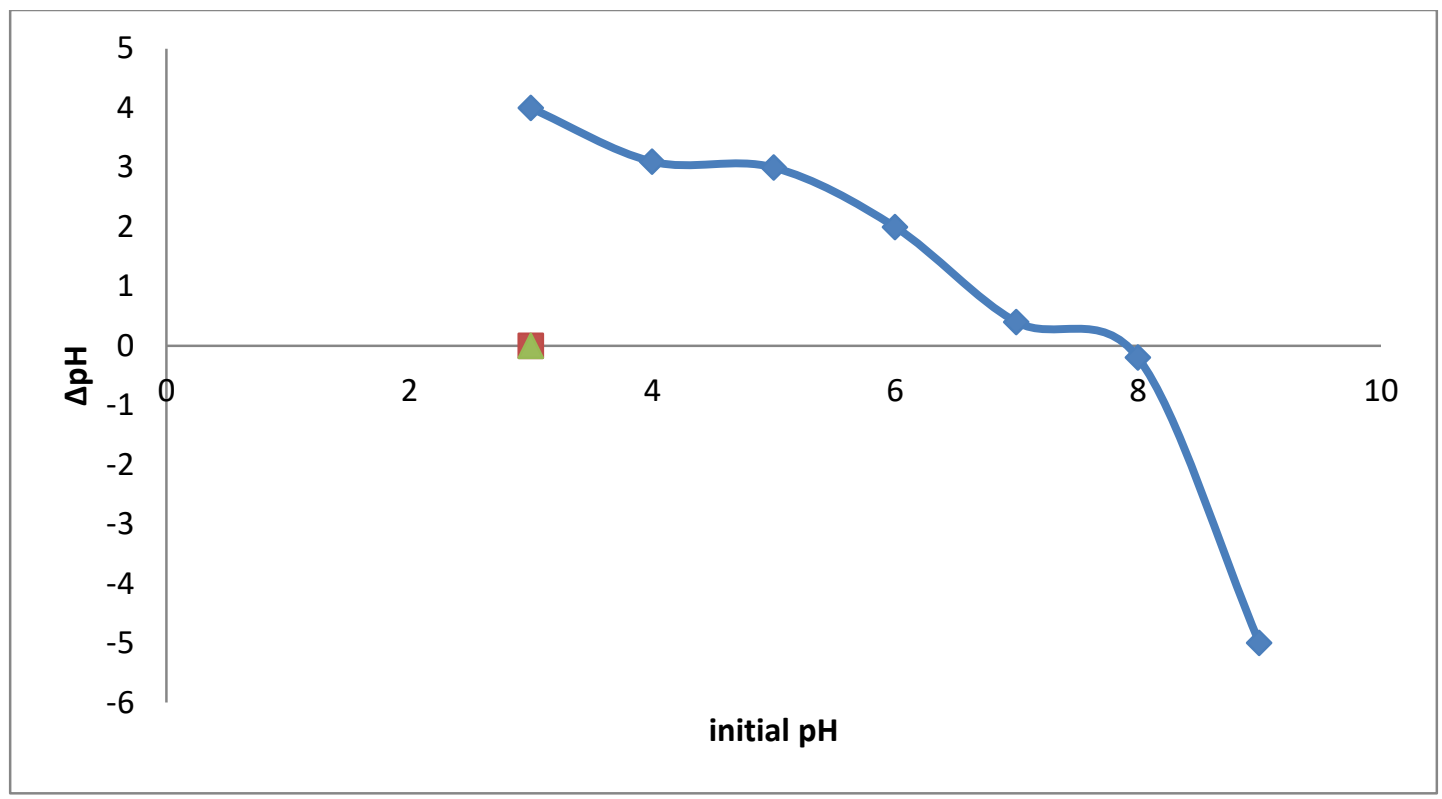

Figure 1: Determination of $\mathrm{pHZpC}$ for the synthesized $\mathrm{ZnFe}_{2} \mathrm{O}_{4} / \mathrm{TiO}_{2}$ composite

Kusvuran et al; 2004 reported that rate of photocatalytic decolorization of azo dyes usually at $\mathrm{pH} 6$ was faster and higher than at $\mathrm{pH} 3$. Assumption can be made that $\mathrm{MG}$ molecule is positively charge; therefore, an electrostatic attraction is established. The $\mathrm{pHZpC}$ for the synthesized $\mathrm{ZnFe}_{2} \mathrm{O}_{4} / \mathrm{TiO}_{2}$ was at $\mathrm{pH}$ value of 8.1, Figure 1. Additionally, strong adsorption can be developed and this can leads to a major decrease of the active centers on surface of the photocatalyst. This also means the absorption of the light quanta by the photocatalyst decreased. Furthermore, the amount decolorization of MG increment may be explained by the fact that at higher $\mathrm{pH}$ the surface of photocatalyst is deprotonated and turn to negatively charge; hence attraction between the positively metal cations established (Lohani et al., 2008). Therefore, $\mathrm{ZnFe}_{2} \mathrm{O}_{4} / \mathrm{TiO}_{2}$ surface is negatively charged in basic media $(\mathrm{pH}>8)$, and then positively charged under acidic conditions $(\mathrm{pH}<8)$

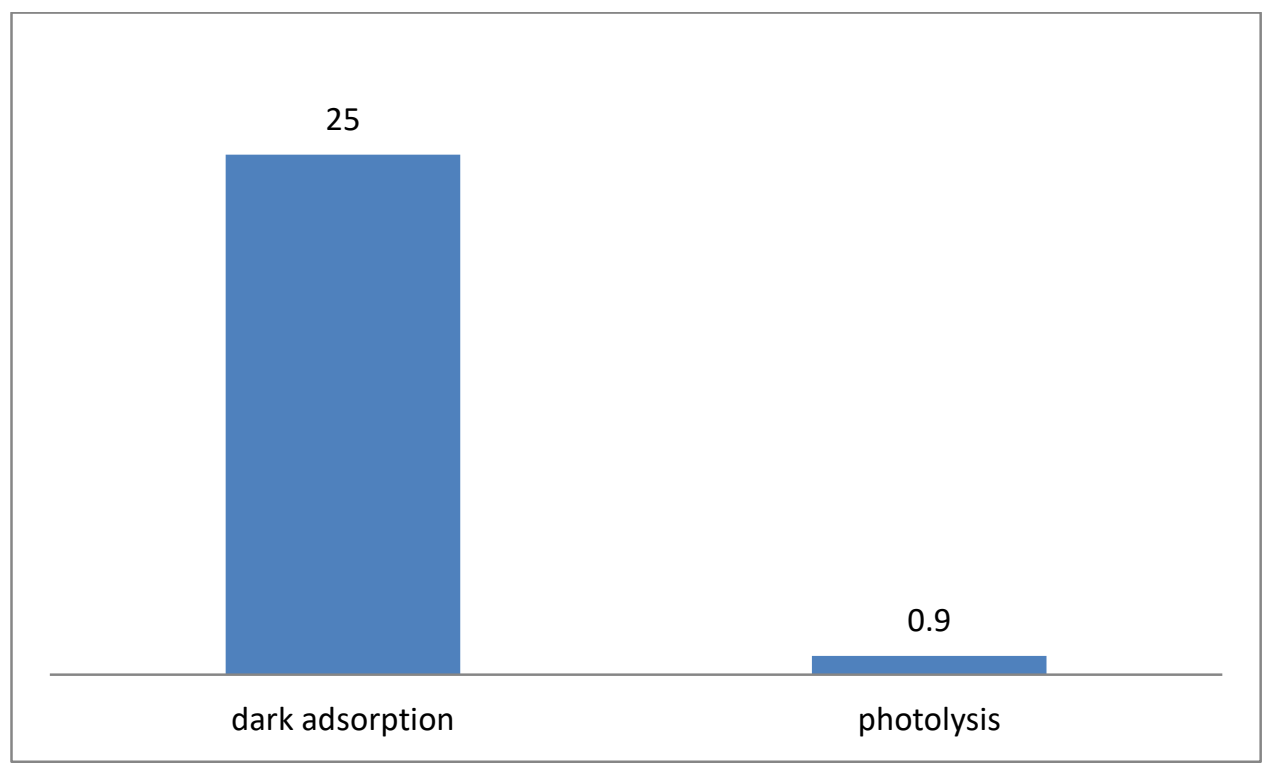

Figure 2: Dark Adsorption. $[M G o]=5 \mathrm{mg} / \mathrm{L}, \mathrm{pH}=5.42, \mathrm{ZnFe}_{2} \mathrm{O}_{4} / \mathrm{TiO}_{2}$ dosage $=0.53 \mathrm{mg} / \mathrm{L}$, Photolysis $[M G o]=5 \mathrm{mg} / \mathrm{L}, \mathrm{pH}=$ 5.42 
Very small changes were observed for the duration of 30 minutes, and $(<1 \%)$ of the MG solution decolorized under visible light alone. This implied that the MG in the solution was very stable to visible light, as it was reported by Tesfaye and Aynalem, (2014). From the results obtained it is also possible to understand that the dye can be adsorbed by the photocatalyst and the adsorption efficiency can also be reached up to $25 \%$ (figure 2). But this is not decolorization because there was no irradiation. Design Expert software 6 has excellent function in color removal based on results obtained experimentally and is given below:

$\mathrm{Y}(\% 100)=-37.23+0.18 \mathrm{~A}+61.28 \mathrm{~B}+1.58 \mathrm{C}+20.32 \mathrm{D}-$ $0.05 \mathrm{~A}^{2}-42.11 \mathrm{~B}^{2}-0.01 \mathrm{C}^{2}-1.78 \mathrm{D}^{2}+0.05 \mathrm{AB}-0.02 \mathrm{AD}-0.02 \mathrm{BD}$
Where initial MG concentration (A), photocatalyst dosage (B), and irradiation time $(\mathrm{C})$, initial $\mathrm{pH}(\mathrm{D})$.

From the derived mathematical model, the ANOVA (see Table 2) showed an F-value of 1114.81 which suggests that the model is significant. All model terms i.e. MG dye initial concentration, photocatalyst dose, irradiation time and $\mathrm{pH}$ are all significant with Prob $>$ " values $<0.05$. The predicted R-squared 0.995 agrees with the Adj R-squared 0.998 . Adequate precision greater than 4.00 by the model shows desirability and indicates adequate signal. F-values implied that MG dye initial concentration has the highest influence in color removal among the other parameters involved.

Table 2. ANOVA using Central Composite Design

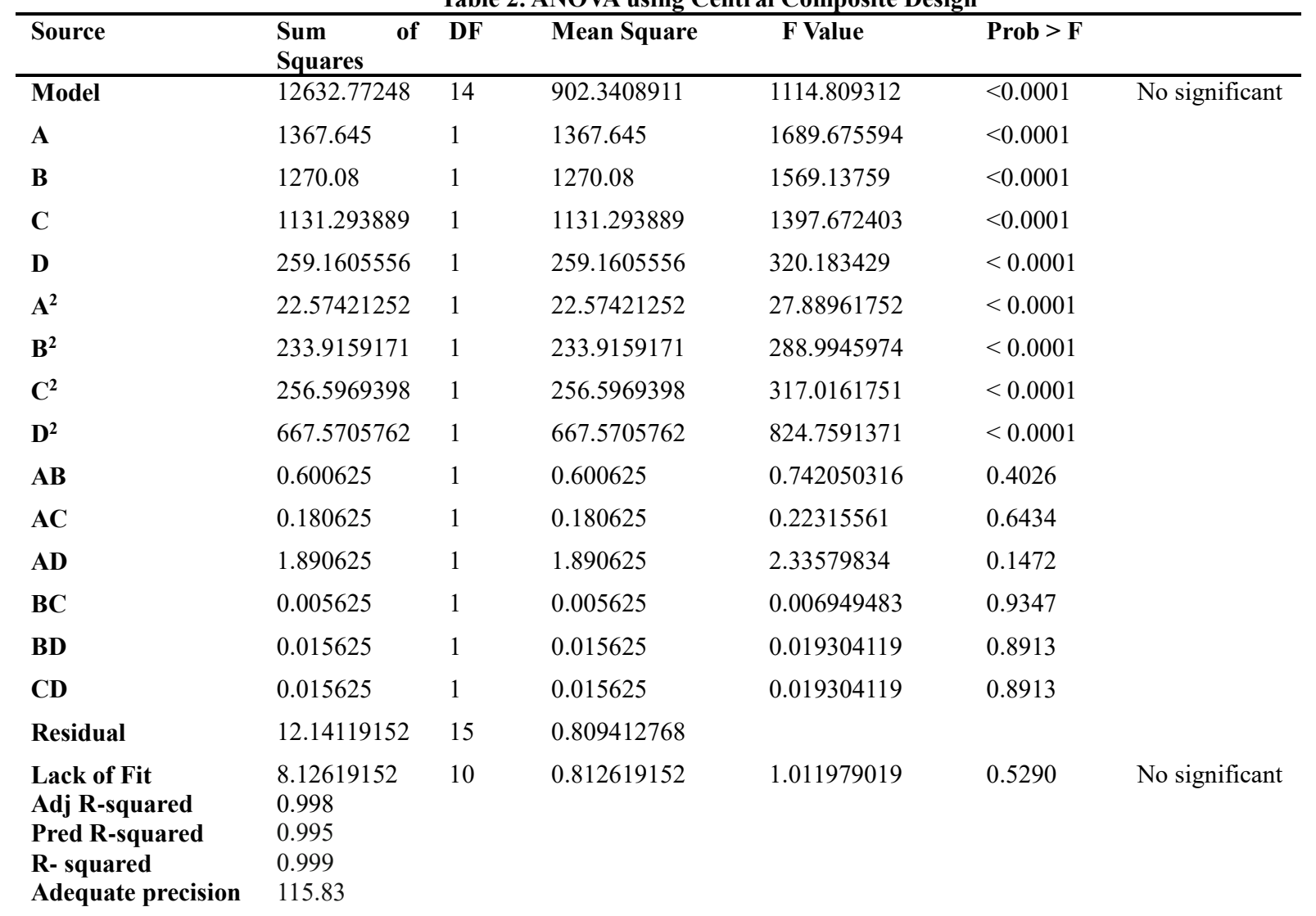

The effect of operating parameters showed that the color removal increases when photocatalyst dose, irradiation time and initial $\mathrm{pH}$ are increased to a certain level then it start decreasing. For instance, the color removal decreases as $\mathrm{MG}$ dye initial concentration, increases. More active sites on surface of the photocatalyst were formed by increasing photocatalyst dose and this cause number of $\bullet \mathrm{OH}$ radicals to multiply and take part in the decolorization of dyes. On the other hand, MG dye initial concentration increases, make dyes adsorption equilibrium on the photocatalyst active sites also increases, hence adsorption competition of $\bullet \mathrm{OH}$ radicals on the same site decreases. This indicate rate of formation of $\bullet \mathrm{OH}$ radical responsible for dye discoloration (Akyol et al., 2004). Path length of quanta passing through the solution decreases, as MG dye initial concentration is increased, this result in deceleration of quanta adsorption by photocatalyst molecules, and hence photocatalytic reaction rates decreases (Habibi and Nasr-Esfahani, 2007). The result also suggests the importance of contact time between the catalyst and target pollutant. The optimum conditions and full factorial central composite design showing the actual and predicted values are presented in Table 3 . 
Table 3: Optimization results of full factorial central composite design.

\begin{tabular}{|c|c|c|c|c|c|c|}
\hline \multirow[b]{3}{*}{$\begin{array}{l}\text { Run } \\
\text { order }\end{array}$} & \multicolumn{2}{|c|}{ Process variables } & \multicolumn{4}{|l|}{ Response } \\
\hline & \multicolumn{6}{|c|}{ \% Decolorization of MG } \\
\hline & Initial dye conc. (A) & $\begin{array}{l}\text { Photocatalyst dose } \\
\text { (B) }\end{array}$ & $\begin{array}{l}\text { Irradiation } \\
\text { time }(\mathbf{C})\end{array}$ & $\begin{array}{l}\text { Initial } \mathrm{pH} \\
\text { (D) }\end{array}$ & $\begin{array}{l}\text { Actual } \\
\text { values }\end{array}$ & $\begin{array}{l}\text { Predicted } \\
\text { values }\end{array}$ \\
\hline 1 & 20 & 0.05 & 90 & 9 & 47.1 & 47.65 \\
\hline 2 & 12.5 & 0.53 & 60 & 6 & 30.3 & 30.31 \\
\hline 3 & 5 & 1 & 30 & 3 & 64.6 & 64.09 \\
\hline 4 & 5 & 0.05 & 30 & 3 & 47.2 & 47.52 \\
\hline 5 & 12.5 & 0.53 & 60 & 9 & 64.2 & 63.2 \\
\hline 6 & 12.5 & 0.53 & 30 & 6 & 45.7 & 46.27 \\
\hline 7 & 12.5 & 0.05 & 60 & 6 & 78.7 & 79.71 \\
\hline 8 & 12.5 & 0.53 & 60 & 6 & 64.7 & 63.56 \\
\hline 9 & 20 & 1 & 90 & 3 & 40.1 & 40.75 \\
\hline 10 & 5 & 0.05 & 90 & 3 & 22.5 & 22.03 \\
\hline 11 & 12.5 & 1 & 60 & 6 & 57.1 & 57.06 \\
\hline 12 & 12.5 & 0.53 & 60 & 6 & 38.1 & 39.12 \\
\hline 13 & 20 & 0.05 & 90 & 3 & 56.2 & 56.42 \\
\hline 14 & 5 & 1 & 90 & 9 & 38.1 & 38.12 \\
\hline 15 & 20 & 1 & 30 & 3 & 73.3 & 72.81 \\
\hline 16 & 20 & 0.05 & 30 & 3 & 55.3 & 55.29 \\
\hline 17 & 5 & 0.53 & 60 & 6 & 95.25 & 96.10 \\
\hline 18 & 12.5 & 0.53 & 60 & 6 & 78.1 & 78.28 \\
\hline 19 & 12.5 & 0.53 & 90 & 6 & 72.6 & 72.07 \\
\hline 20 & 20 & 0.05 & 30 & 9 & 88.5 & 88.85 \\
\hline 21 & 12.5 & 0.53 & 60 & 6 & 73.1 & 72.07 \\
\hline 22 & 20 & 1 & 90 & 9 & 87.1 & 87.93 \\
\hline 23 & 5 & 1 & 90 & 3 & 77.5 & 77.69 \\
\hline 24 & 20 & 0.53 & 60 & 6 & 70.5 & 70.1 \\
\hline 25 & 5 & 1 & 30 & 9 & 89.2 & 89.95 \\
\hline 26 & 12.5 & 0.53 & 60 & 3 & 90.2 & 89.95 \\
\hline 27 & 5 & 0.05 & 30 & 9 & 89.5 & 89.95 \\
\hline 28 & 5 & 0.05 & 90 & 9 & 91.2 & 89.95 \\
\hline 29 & 12.5 & 0.53 & 60 & 6 & 90.3 & 89.95 \\
\hline 30 & 20 & 1 & 30 & 9 & 88.7 & 89.95 \\
\hline
\end{tabular}

Therefore, RSM result predicted 96.1\%. After laboratory work was conducted in line with optimized parameters, 95.3\% decolorization was obtained as the actual value. Agreement between the predicted results and laboratory results indicated that $\mathrm{CCD}$ design is viable for optimization of $\mathrm{MG}$ decolorization. 
Optimization and Response surface (contour) plots

RSM is a mathematical approach to examine the overall shape of the curve, to locate the stationary point of the response surface, and to decide whether it describes a maximum, minimum, or saddle point. Three-dimensional (3D) and contour (2D) plots for the predicted responses were also formed, based on the model polynomial functions to assess the change of the response surface as shown in Figures $3 a-6 b$. The relationship between the dependent and independent variables can be also further understood by these plots. Since the model has more than two factors, one factor was held constant for each diagram.

\section{DESIGN-EXPERT Plot \\ degradation \\ - Design Points \\ $X=A:$ conc \\ $Y=C:$ time \\ Actual Factors \\ B: dose $=0.53$ \\ $\mathrm{D}: \mathrm{pH}=6.00$}

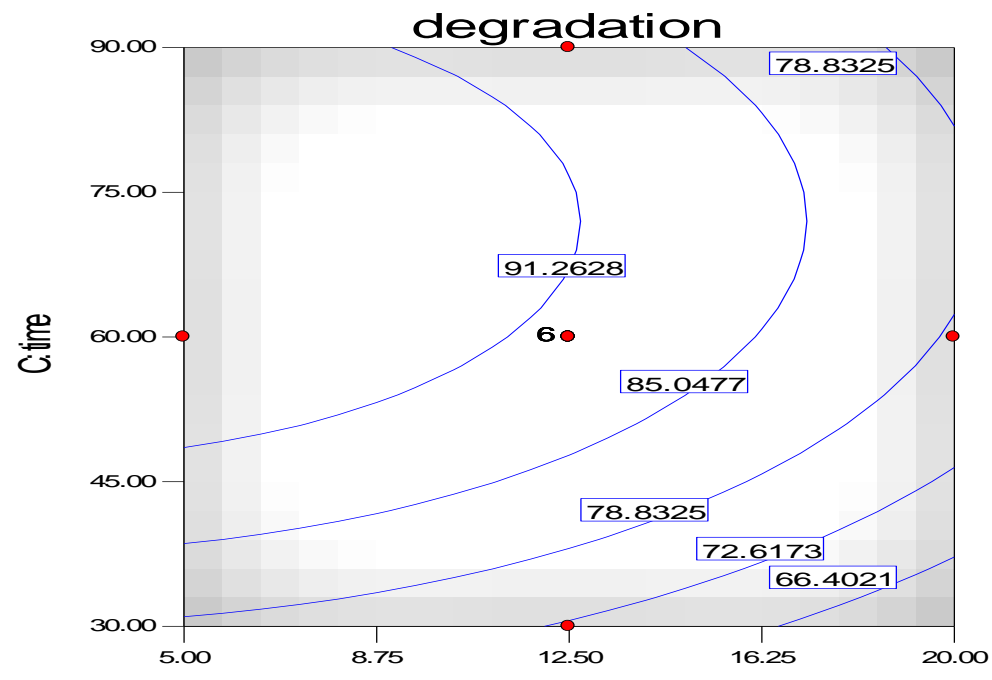

A: conc

Figure 3a. Contour plot of Simultaneous effects of the initial MG concentration and irradiation time on the decolorization of MG using $\mathrm{ZnFe}_{2} \mathrm{O}_{4} / \mathrm{TiO}_{2}$

\section{deg radation \\ $X=A:$ conc
$Y=C:$ time \\ Actual Factors \\ $\mathrm{B}:$ dose $=0.53$}

DESIGN-EXPERT PIOT

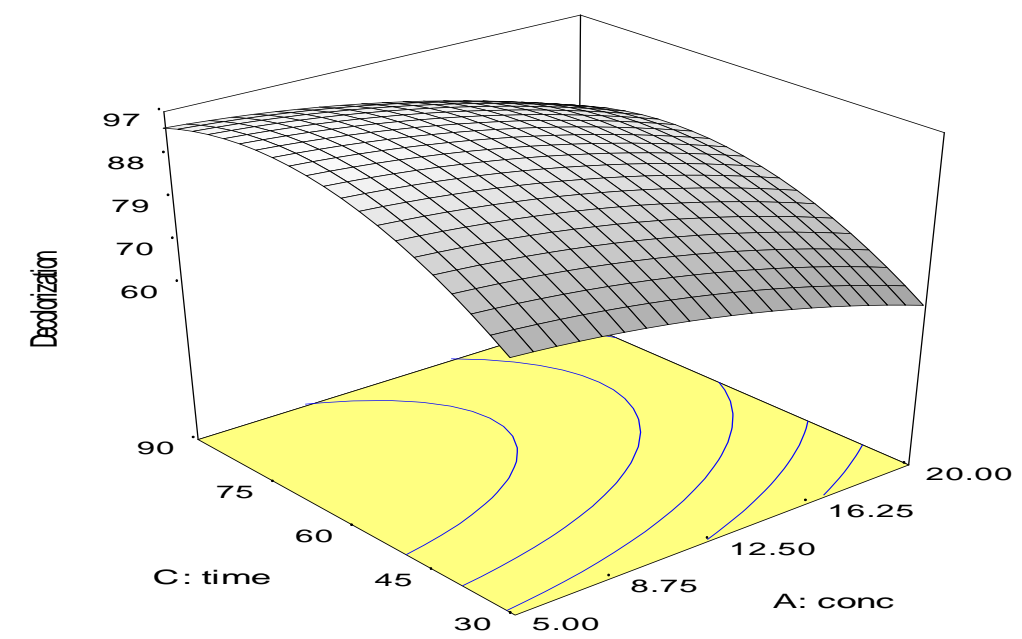

Figure 3b: 3D Simultaneous effects of the initial MG concentration and irradiation time on the decolorization of $\mathrm{MG}$ using $\mathrm{ZnFe}_{2} \mathrm{O}_{4} / \mathrm{TiO}_{2}$ 

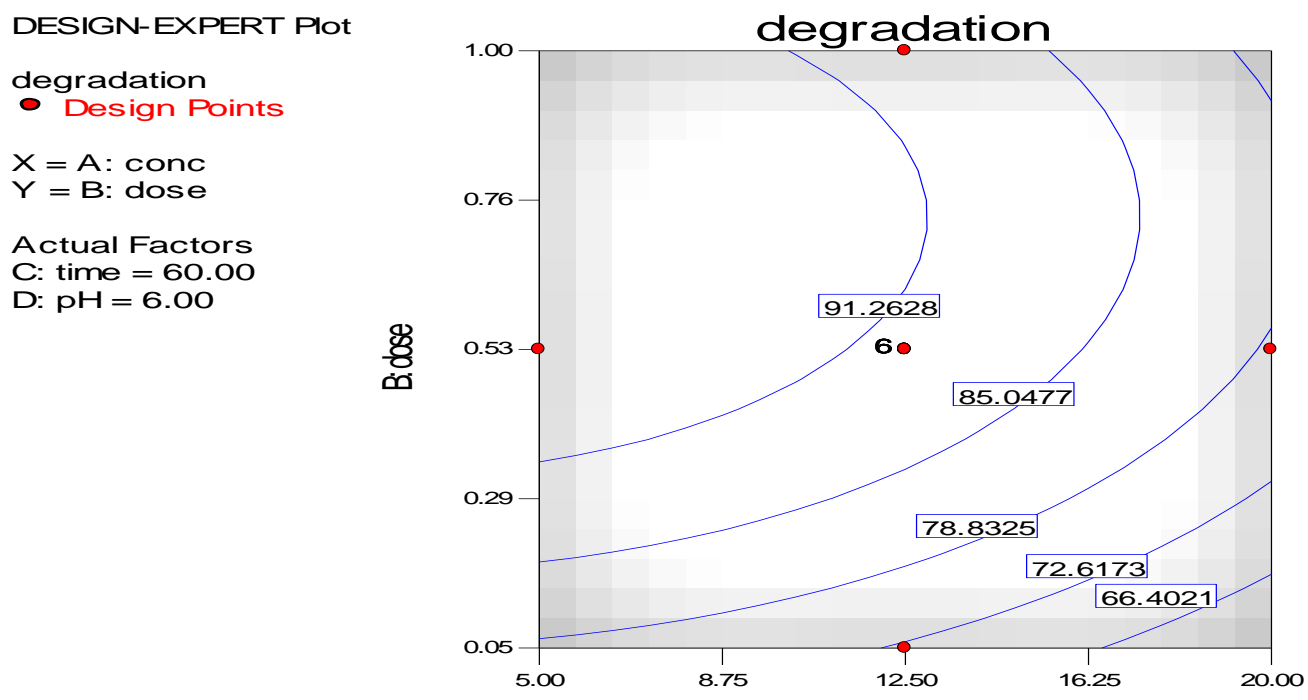

A: conc

Figure 4a: Contour plot of Simultaneous effects of the initial MG concentration and photocatalyst dosage on the decolorization of MG using $\mathrm{ZnFe}_{2} \mathrm{O}_{4} / \mathrm{TiO}_{2}$

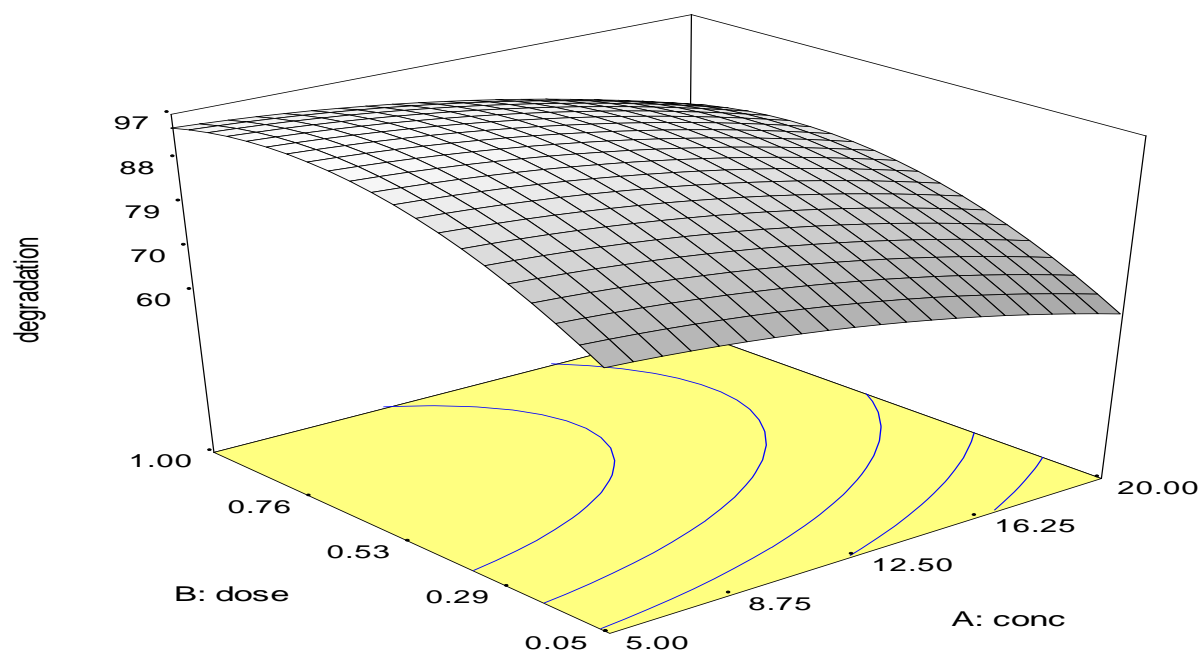

Figure 4b: 3D Simultaneous effects of the initial MG concentration and photocatalyst dose on the decolorization of MG using $\mathrm{ZnFe}_{2} \mathrm{O}_{4} / \mathrm{TiO}_{2}$. 
DESIGN-EXPERT Plot

degradation

- Design Points

$X=B:$ dose

$\mathrm{Y}=\mathrm{D}: \mathrm{pH}$

Actual Factors

A: conc $=12.50$

C: time $=60.00$

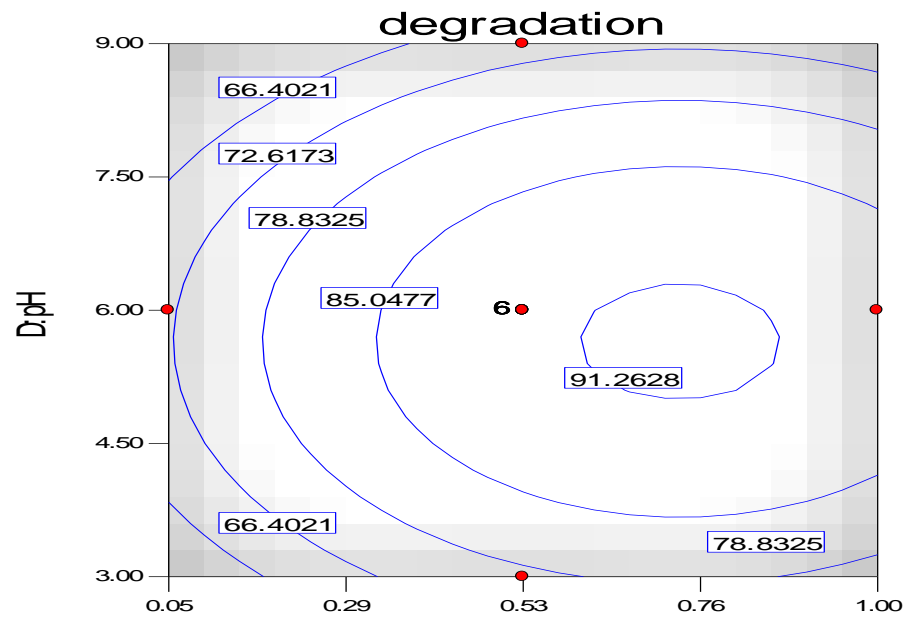

B: dose

Figure 5a: Contour plot of Simultaneous effects of the initial $\mathrm{MG} \mathrm{pH}$ and photocatalyst dosage on the decolorization of $\mathrm{MG}$ using $\mathrm{ZnFe}_{2} \mathrm{O}_{4} / \mathrm{TiO}_{2}$

\section{DESIGN-EXPERT PIOt}

\section{deg radation \\ $X=B:$ dose \\ $\mathrm{Y}=\mathrm{D}: \mathrm{pH}$}

Actual Factors

A: conc $=12.50$

C: time $=60$

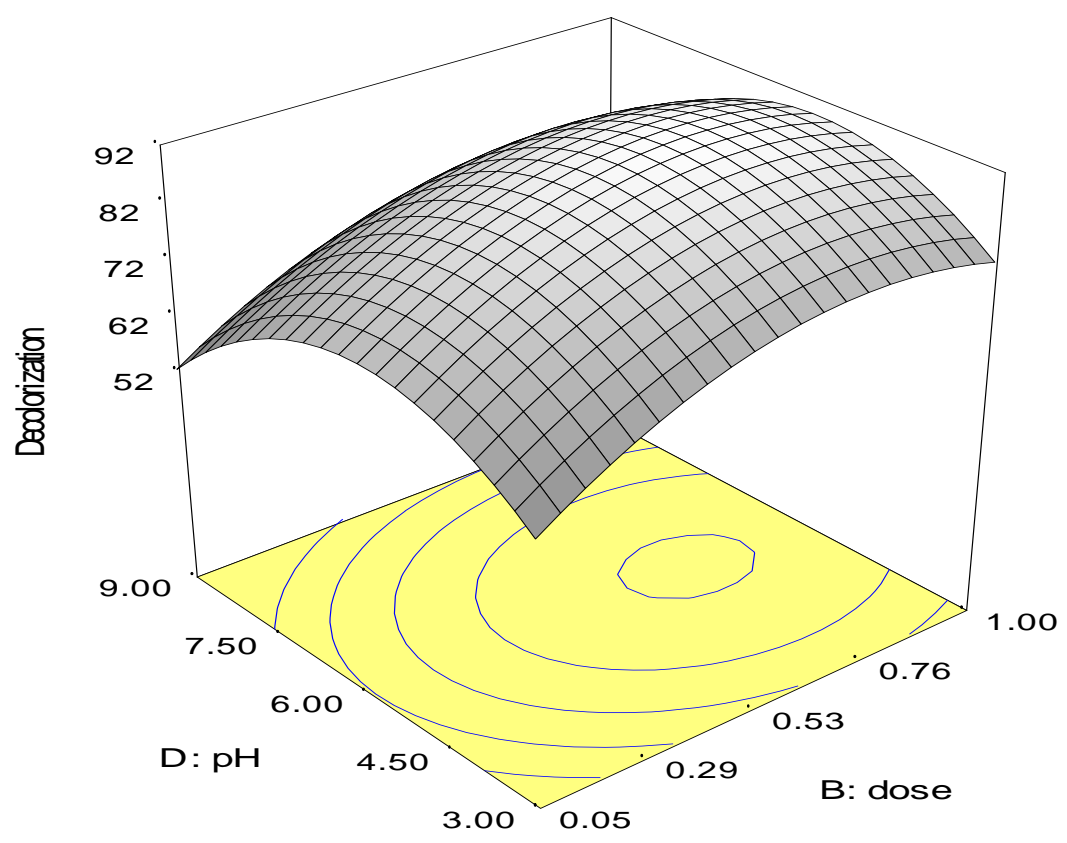

Figure 5b: 3D Simultaneous effects of the photocatalyst dose and $\mathrm{pH}$ on the decolorization of $\mathrm{MG}$ using $\mathrm{ZnFe}_{2} \mathrm{O}_{4} / \mathrm{TiO}_{2}$ 
DESIGN-EXPERT Plot

degradation

- Design Points

$X=A:$ conc

$\mathrm{Y}=\mathrm{D}: \mathrm{pH}$

Actual Factors

B: dose $=0.53$

C: time $=60$.00

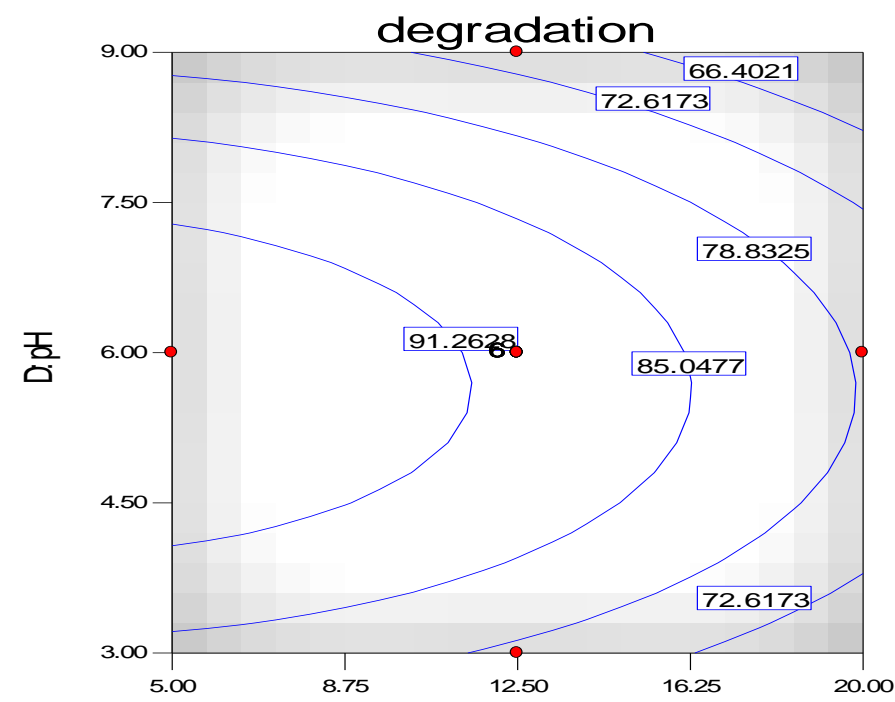

A: conc

Figure 6a: Contour plot of Simultaneous effects of the initial MG concentration and initial MG pH on the decolorization of $\mathrm{MG}$ using $\mathrm{ZnFe}_{2} \mathrm{O}_{4} / \mathrm{TiO}_{2}$

\section{DESIGN-EXPERT PIOt}

\section{deg radation \\ $X=A$ : conc \\ $Y=D: p H$ \\ Actual Factors \\ $\mathrm{B}:$ dose $=0.53$ \\ C: time $=60$}

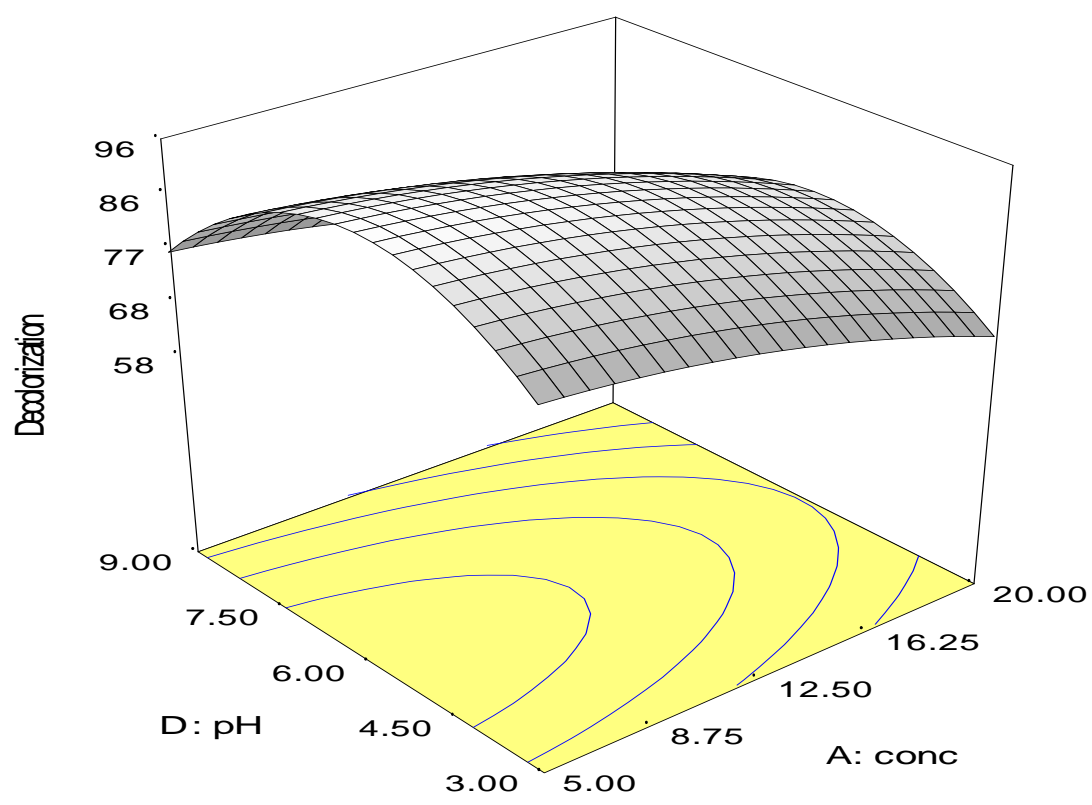

Figure 6b: 3D Simultaneous effects of the initial $\mathrm{MG}$ concentration and initial $\mathrm{MG} \mathrm{pH}$ on the decolorization of $\mathrm{MG}$ using $\mathrm{ZnFe}_{2} \mathrm{O}_{4} / \mathrm{TiO}_{2}$

\section{CONCLUSIONS}

It was concluded from the analysis that the synthesized $\mathrm{ZnFe}_{2} \mathrm{O}_{4} / \mathrm{TiO}_{2}$ composite has a specific surface area 243.80 $\mathrm{m}^{2} \mathrm{~g}^{-1}$ and $\mathrm{P}_{\mathrm{HpZC}}$ 8.1.The material has rough surfaces, and the particles are of non-uniform shape and size as the SEM image implies. In laboratory investigation, the model derived for this system is significant with an $F$-value of 1114.81. ANOVA implied a high coefficient of determination $\left(\mathrm{R}^{2}=0.999\right)$, indicating a satisfactory fit between the second order regression model and the experimental results. The predicted R-squared of 
0.995 is a reasonable agreement with the adjusted R-squared of 0.998 , adequate precision greater than 4.00 shows that it is desirable and indicates an adequate signal.

Only $0.9 \%$ of it decolorized within irradiation period of one hour figure 2 . The synthesized photocatalyst adsorbs $25 \%$ of the MG in the dark with one hour of contact. The optimal conditions, which yielded a maximized MG decolorization of $95.3 \%$, were carried out in replicate, and identified using RSM with Design-Expert software v 6, these determined as follows: photocatalyst dosage of $0.53 \mathrm{~g} / \mathrm{L}, \mathrm{pH}$ of 5.48 , irradiation time of 90 minutes, and initial MG concentration of $5.12 \mathrm{mg} / \mathrm{L}$.

\section{REFERENCES}

Akyol, A., Yatmaz, H., and Bayramoglu, M. (2004): Photocatalytic decolorization of Remazo red RR in aqueous $\mathrm{ZnO}$ suspensions. Applied Catalysis B: Environmental, 54(1), 19-24.

Aplin R, Waite TD. (2000): Comparison of three advanced oxidation processes for degradation of textile dyes. Water Science and Technology ; 42 (5):34-554.

Arana, J., Dona-Rodrigues, J., Rendon, E., Cabo, C., GonzalesDiaz, O., Herrera-Melian, J., Perez-Pena, J., Colon, G., and Navio, A. (2008): $\mathrm{TiO}_{2}$ activation by using activated carbon as a support Part I. Surface characterization and decantability study. Applied Catalysis B: Environmental, 44(2), 161.

Behnajady, M., Daneshvar, N., and Rabbani, M. (2007): Photocatalytic degradation of CI Red 27 by immobilized $\mathrm{ZnO}$ on glass plates in continuous mode. Journal of Hazardous Materials, 140(1), 257-263.

Farahmandjou, M., khalili, P. (2013): Morphology Study of anatase nano- $\mathrm{TiO}_{2}$ for Self-cleaning Coating. IJFPS, Vol 3, No 3 , pp 54-56.

Gallo, J., Mariquit, E., Co, R., Borja, J., and Gallardo, S. (2008): Assessment of the colored wastewater treatment in the Philippine textile industry and preliminary study on the color removal of wastewater using photocatalysis. Manila, Philippines. 65(1), 23-29

Habibi, M., and Nasr-Esfahani, M. (2007): Preparation, characterization and photocatalytic activity of a novel nanostructure composite film derived from nanopowder $\mathrm{TiO}_{2}$ and sol-gel process using organic dispersant. Dyes and Pigments, 75(3), 714-722.
Han, F.; Kambala, V.; Srinivasan, M.; Rajarathnam, D.; and Naidu, R. (2008): Tailored Titanium dioxide photocatalysts for the degradation of organic dyes in wastewater treatment: A review. Applied Catalysis A: General, 359(1), 25-40.

Kusvuran E., Gulnaz O., Irmak S, Atanur OM., Yavuz HI., Erbatur O. (2004): Comparison of several advanced oxidation processes for the decolorization of Reactive Red 120 azo dye in aqueous solution. Journal of Hazardous Materials; 109: 85-93.

Lohani M.B., Singh A., Rupainwar D.C., and Dhar D.N. (2008): Studies on efficiency of guava (Psidiumguajava) bark as bioadsorbent for removal $\mathrm{Hg}$ (II) from aqueous solutions, Journal of Hazard Mater., 159, 626-629.

Mahmood, T., Saddique, M. T., Naeem, A., Westerhorff, P., Mustafa, S. and Alum, A. (2011): Utilization of pine Nut shell derived carbon as an efficient alternate for the sequestration of phthalates from aqueous system. Ind. Eng. Chem. Res., 50: 1017.

Masten SJ, Davies SHR. (1994): The use of ozonation to degrade organic contaminants in wastewaters. Water Science and Technology; 28(4):180-500.

Moraes SG, Freire RS, Duran N. (2000): Degradation and toxicity reduction of textile effluent by combined photocatalytic and ozonation processes. Chemosphere; 40(4):369-730.

Rezaee, A., Darvishi Cheshmeh Soltani, R., Khataee, A. R., Godini H. (2012): Optimization of combined photocatalytic involving immobilized $\mathrm{ZnO}$ nanoparticles and electrochemical processes for ammoniacal nitrogen removal from aqueous solutions J. Mater. Environ. Sci. 3 (5) 955-966.

Tesfaye Teka, Aynalem Reda, (2014): Comparative Study on the Photocatalytic Degradation of Malachite Green Using Zinc Oxide under Different Sources of Radiation, international journal of technology enhancements and emerging engineering research, vol 2, 2347-4289.

Uygur A. (1997): An overview of oxidative and photooxidative decolorization treatments of textile waste waters. Journal of the Society of Dyers and Colorists; 113: 211-700. use, distribution, and reproduction in any medium, provided the original work is cited appropriately. 